\title{
Decay Characteristics of Neutron Excess Zinc Nuclei
}

\author{
Joseph Bevelacqua
}

Funding: The author(s) received no specific funding for this work.

Potential competing interests: The author(s) declared that no potential competing interests exist.

\section{Abstract}

In neutron star mergers, neutron excess nuclei and the r-process are important factors governing the production of heavy nuclear systems. An evaluation of zinc nuclei suggests that the heaviest $Z=30$ nucleus will have mass 88 with filling of the $3 s_{1 / 2}$ neutron shell. $A=84-88$ zinc isotopes have limited experimental half-life data, but the model predicts beta decay half-lives in the range of $60-100 \mathrm{~ms}$. Based on comparisons to $Z=20$ and $Z=26$ systems, these results likely overestimate the experimental half-lives of these $A=84-88$ neutron excess zinc nuclei.

\subsection{Introduction}

The nucleosynthesis of heavy elements occurs by three basic processes that add protons or neutrons to a nuclear system $^{1,2}$. The $\mathrm{p}$-process adds protons and the $\mathrm{s}$ - or slow process and $\mathrm{r}$ - or rapid process adds neutrons. Capture of protons by nuclear systems produces predominantly proton-rich nuclei that tend to decay by positron emission and electron capture ${ }^{1,2}$. Neutron capture creates neutron-rich nuclei, and the resulting nuclear system depends upon the rate of neutron addition and the beta decay rates of the residual nuclei.

In the s-process neutron capture chain, the time between successive neutron captures is sufficiently long for the product nucleus to beta decay to a stable system. Within the r-process, the time between neutron captures is too short to permit decays except for very rapid beta transitions. Therefore, the r-process must occur in an environment that has a high density of neutrons. The s-process typically occurs in red giant stars. The r-process occurs in a variety of astronomical events, including supernovae explosions and stellar mergers.

Binary neutron star or neutron star and stellar-mass black hole mergers can form a massive rotating torus around a spinning black hole ${ }^{1}$. The matter ejected from these structures and from supernovae explosions is an important source of rapid neutron capture (r-process) nucleosynthesis ${ }^{1}$. Fully understanding the r-process requires knowledge of the properties of neutron excess nuclei involved in creating heavy nuclear systems. Unfortunately, the majority of these neutron excess systems have never been studied ${ }^{2}$.

Closing this knowledge gap was a motivation for funding facilities for rare-isotope beams constructed at research facilities located around the world ${ }^{3-8}$. These facilities enable a new class of experiments to determine the physical properties needed by theoretical models to determine the structure of unstable neutron excess nuclei. Theoretical studies would complement the forthcoming experiments that will provide critical information on the unstable nuclei that must be understood in order to explain nuclear abundances observed in the universe ${ }^{2}$. In particular, the study of neutron excess 
systems and their decay properties are important considerations in understanding the r-process, and its importance in producing the observed elements in the universe.

The study of neutron excess systems is also important for evaluating nuclear decay properties, nuclear structure under extreme conditions, and nuclear reaction mechanisms. Existing theoretical models have not been extensively applied to many of these neutron excess nuclei.

This paper attempts to partially fill this void by calculating the decay properties of neutron excess systems that are important in nucleosynthesis. These theoretical studies should also assist in planning future experiments associated with neutron excess systems that are far removed from the line of stability.

Neutron excess nuclei that merit study occur throughout the periodic table ${ }^{2-8}$ including nuclei in the $11 \leq Z \leq 32$ range $^{8}$. Previous studies provided half-life and structure calculations for neutron excess calcium ${ }^{9}$ and iron ${ }^{10}$ systems. This paper extends the approach of Refs. 9 and 10 to zinc systems as an additional investigation of neutron excess nuclei that are of potential astrophysical significance. An additional study of neutron excess fluorine systems ${ }^{11}$ was performed using a similar methodology.

\subsection{Calculational Methodology}

A variety of models could be applied to the investigation of neutron excess nuclei. These models vary in sophistication, but the proposed model utilizes a basic single-particle approach. This is a reasonable first step because there are uncertainties in the nuclear potential that likely are more significant than the limitations introduced by a singleparticle approach.

Since the method for calculating single-particle energies in a spherically symmetric potential is well-established, only salient features are provided. The model used to describe the particle plus core system represents an application of the standard method of Lukasiak and Sobiczewski ${ }^{12}$ and Petrovich et al. ${ }^{13}$

The binding energy $E_{\text {NLSJ }}$ of a particle in the field of a nuclear core is obtained by solving the radial Schrödinger Equation

$$
\left[\frac{h^{2}}{2(2 \pi)^{2} \mu}\left(\frac{d^{2}}{d r^{2}}-\frac{L(L+1)}{r^{2}}\right)-E_{N L S J}-V_{L S J}(r)\right] U_{N L S J}(r)=0(1)
$$

where $r$ is the radial coordinate defining the relative motion of the nuclear core and the particle; $V_{L S J}(r)$ is the model interaction; $E_{N L S J}$ is the core plus particle binding energy; $U_{N L S J}(r)$ is the radial wave function; and $L, S$, and $J$ are the orbital, spin, and total angular momentum quantum numbers, respectively. The $\mathrm{N}$ quantum number is the radial quantum number, and $\mu$ is the reduced mass. Additional details of the model, as applied to neutron excess nuclei, are provided in Ref. 9.

\subsection{Nuclear Interaction}

Nuclear stability with respect to alpha decay, beta decay, positron decay, and electron capture is addressed using the method previously published by the author and coworkers ${ }^{13}$ that is similar to the approach of Ref. 14 . The singleparticle level spectrum is generated using a Woods-Saxon potential based on the Rost interaction ${ }^{15}$.

The Rost interaction yields reasonable fits to observed single-particle levels in ${ }^{120} \mathrm{Sn}$ and ${ }^{138} \mathrm{Ba}$. The pairing 
correction term of Blomqvist and Wahlborn ${ }^{16}$ is used in the calculations presented herein. The pairing correction improves the predicted energies of occupied levels in ${ }^{120} \mathrm{Sn},{ }^{138} \mathrm{Ba}$, and ${ }^{208} \mathrm{~Pb}^{13}$.

When applied to zinc nuclei, this methodology requires modification. Ray and Hodgson ${ }^{17}$ note that ${ }^{40} \mathrm{Ca}$ and ${ }^{48} \mathrm{Ca}$ require different potentials to properly fit their structure. Schwierz, Wiedenhöver, and Volya ${ }^{18}$ also investigated ${ }^{40} \mathrm{Ca}$ and ${ }^{48} \mathrm{Ca}$ and noted that a proper fit to the single-particle levels required a different potential for each energy level. Difficulties in the selection of an appropriate potential is an additional motivation for the utilization of single-particle levels in this study of neutron excess zinc nuclei. Similar issues in calculating the nuclear structure are noted for ${ }^{70} \mathrm{Fe}, \mathrm{Z}=56-80$ systems ${ }^{19,20}$, and in the zinc system for mean field and dispersive optical potential models ${ }^{21,22}$. The importance of nuclear correlations in describing the structure of ${ }^{71} \mathrm{Zn}$ was noted in Ref. 23 . The results in zinc and neighboring systems suggest that collective effects ${ }^{19}$ and nuclear correlations ${ }^{23}$ will also become important in zinc systems as the neutron number increases. These effects require the alteration of the nuclear potential as noted in Refs. 9 - 11, 17, 18, and 21 - 23.

In view of the results of Refs. $9-11$ and $17-23$, the following modification is made to the Rost interaction:

$$
V_{0}=51.6\left[1 \pm 0.73^{\frac{N-Z}{A}}\right][1 \pm a(A)] \operatorname{MeV}(2)
$$

where $\mathrm{a}(\mathrm{A})$ is a constant that was introduced in Ref. 9 to account for the variations in potential strength with $\mathrm{A}^{17-20}$. It is preferable that $\mathrm{a}(\mathrm{A})$ be constant for as many zinc isotopes as possible. Since the paper's primary purpose is investigation of the neutron excess nuclei, determining a common a $(A)$ value for the heaviest zinc systems is desirable.

\subsection{Calculation of Half-Lives}

Using Eq. 1, single-particle levels are calculated for $A \geq 54$ zinc isotopes. $A \geq 54$ zinc nuclei were evaluated for stability with respect to alpha decay, beta decay, positron decay, electron capture, and two-proton (2p) decay. These calculations were performed to ensure that the nuclear structure contained no interloping states or structural defects, and that any decay modes in conflict with data were identified.

The decay modes and half-lives of $88 \geq A \geq 54$ zinc isotopes are summarized in Table I and compared to available data $^{24,25}$. The alpha decay energies are calculated using the relationship based on Ref. 26.

$$
Q_{\alpha}=28.3 \mathrm{MeV}-2 S_{n}-2 S_{p}(3)
$$

where $S_{n}$ and $S_{p}$ are the binding energies of the last occupied neutron and proton single-particle levels, respectively. Alpha half-lives can be estimated from $Q_{\alpha}$ using standard relationships ${ }^{12}$. No alpha decay modes occur in the Table I summary of $88 \geq A \geq 54$ zinc isotope decay properties. 
Table I

Calculated Single-Particle and Experimental Decay Properties of Zinc Systems with $54 \leq \mathrm{A} \leq 88$

\begin{tabular}{|c|c|c|c|}
\hline \multirow{2}{*}{ Nuclide } & \multirow{2}{*}{$a(A)$} & \multicolumn{2}{|c|}{ Half-Life (Decay Mode) } \\
\hline & & Experiment & This Work \\
\hline${ }^{54} \mathrm{Zn}$ & a & $3 \mathrm{~ms}(2 p)^{b}$ & $4.35 \mathrm{~ms}(2 p)$ \\
\hline${ }^{55} \mathrm{Zn}$ & +0.085 & $20 \mathrm{~ms}\left(\beta^{+}\right)^{\mathrm{b}}$ & $956 \mathrm{~ms}\left(\beta^{+}\right)^{\mathrm{c}}$ \\
\hline${ }^{56} \mathrm{Zn}$ & +0.06 & $30 \mathrm{~ms}\left(\beta^{+}\right)^{\mathrm{b}}$ & $764 \mathrm{~ms}\left(\beta^{+}\right)^{\mathrm{C}}$ \\
\hline${ }^{57} \mathrm{Zn}$ & +0.035 & $45 \mathrm{~ms}\left(\beta^{+}\right)^{\mathrm{b}}$ & $609 \mathrm{~ms}\left(\beta^{+}\right)^{\mathrm{C}}$ \\
\hline${ }^{58} \mathrm{Zn}$ & +0.01 & $80 \mathrm{~ms}\left(\beta^{+}\right)^{\mathrm{b}}$ & $694 \mathrm{~ms}\left(\beta^{+}\right)^{\mathrm{d}}$ \\
\hline${ }^{59} \mathrm{Zn}$ & -0.015 & $183 \mathrm{~ms}\left(\beta^{+}\right)^{\mathrm{b}}$ & $541 \mathrm{~ms}\left(\beta^{+}\right)^{\mathrm{d}}$ \\
\hline${ }^{60} \mathrm{Zn}$ & +0.11 & $2.40 \min \left(\beta^{+}\right)^{b}$ & $2.42 \min \left(\beta^{+}\right)^{d}$ \\
\hline${ }^{61} \mathrm{Zn}$ & +0.09 & $1.485 \min \left(\beta^{+}\right)^{b}$ & $1.33 \min \left(\beta^{+}\right)^{d}$ \\
\hline${ }^{62} \mathrm{Zn}$ & +0.08 & $9.22 \mathrm{~h}\left(\beta^{+}\right)^{\mathrm{b}}$ & $3.53 h\left(\beta^{+}\right)^{d}$ \\
\hline${ }^{63} \mathrm{Zn}$ & +0.06 & $38.5 \min \left(\beta^{+}\right)^{b}$ & $32.6 \min \left(\beta^{+}\right)^{\mathrm{e}}$ \\
\hline${ }^{64} \mathrm{Zn}$ & +0.075 & Stable ${ }^{b}$ & Stable \\
\hline${ }^{65} \mathrm{Zn}^{f}$ & +0.057 & $244 d(E C)^{b}$ & $258 d(E C)$ \\
\hline${ }^{66} \mathrm{Zn}$ & +0.05 & Stable ${ }^{b}$ & Stable \\
\hline${ }^{67} \mathrm{Zn}$ & +0.05 & Stable ${ }^{b}$ & Stable \\
\hline${ }^{68} \mathrm{Zn}$ & +0.04 & Stable $e^{b}$ & Stable \\
\hline
\end{tabular}


Table I (Continued)

Calculated Single-Particle and Experimental Decay Properties of Zinc Systems with $54 \leq \mathrm{A} \leq \mathbf{8 8}$

\begin{tabular}{|c|c|c|c|}
\hline \multirow{2}{*}{ Nuclide } & \multirow{2}{*}{$a(A)$} & \multicolumn{2}{|c|}{ Half-Life (Decay Mode) } \\
\hline & & Experiment & This Work \\
\hline${ }^{69} \mathrm{Zn}$ & +0.03 & $56 \min \left(\beta^{-}\right)^{b}$ & $66.2 \min \left(\beta^{-}\right)^{g}$ \\
\hline${ }^{70} \mathrm{Zn}$ & +0.00 & Stable ${ }^{b}$ & Stable \\
\hline${ }^{71} \mathrm{Zn}$ & +0.03 & $2.4 \min \left(\beta^{-}\right)^{b}$ & $2.21 \min \left(\beta^{-}\right)^{g}$ \\
\hline${ }^{72} \mathrm{Zn}^{\dagger}$ & -0.008 & $46.5 \mathrm{~h}\left(\beta^{-}\right)^{\mathrm{b}}$ & $44.2 \mathrm{~h}\left(\beta^{-}\right)^{\mathrm{h}}$ \\
\hline${ }^{73} \mathrm{Zn}$ & +0.030 & $24 \mathrm{~s}\left(\beta^{-}\right)^{\mathrm{b}}$ & $23.7 \mathrm{~s}\left(\beta^{-}\right)^{\mathrm{g}}$ \\
\hline${ }^{74} \mathrm{Zn}$ & 0.005 & $1.6 \min \left(\beta^{-}\right)^{b}$ & $1.64 \min \left(\beta^{-}\right)^{g}$ \\
\hline${ }^{75} \mathrm{Zn}$ & 0.025 & $10.2 \mathrm{~s}\left(\beta^{-}\right)^{\mathrm{b}}$ & $9.98 \mathrm{~s}\left(\beta^{-}\right)^{\mathrm{g}}$ \\
\hline${ }^{76} \mathrm{Zn}$ & 0.025 & $5.7 \mathrm{~s}\left(\beta^{-}\right)^{\mathrm{b}}$ & $6.09 \mathrm{~s}\left(\beta^{-}\right)^{\mathrm{g}}$ \\
\hline${ }^{77} \mathrm{Zn}$ & 0.04 & $2.1 \mathrm{~s}\left(\beta^{-}\right)^{\mathrm{b}}$ & $2.07 \mathrm{~s}\left(\beta^{-}\right)^{\mathrm{g}}$ \\
\hline${ }^{78} \mathrm{Zn}$ & 0.04 & $1.5 \mathrm{~s}\left(\beta^{-}\right)^{\mathrm{b}}$ & $1.49 \mathrm{~s}\left(\beta^{-}\right)^{\mathrm{g}}$ \\
\hline${ }^{79} \mathrm{Zn}$ & 0.045 & $1.0 \mathrm{~s}\left(\beta^{-}\right)^{\mathrm{b}}$ & $0.941 \mathrm{~s}\left(\beta^{-}\right)^{\mathrm{g}}$ \\
\hline${ }^{80} \mathrm{Zn}$ & 0.055 & $0.54 \mathrm{~s}\left(\beta^{-}\right)^{\mathrm{b}}$ & $0.539 \mathrm{~s}\left(\beta^{-}\right)^{\mathrm{g}}$ \\
\hline${ }^{81} \mathrm{Zn}$ & 0.065 & $0.32 \mathrm{~s}\left(\beta^{-}\right)^{\mathrm{b}}$ & $0.332 \mathrm{~s}\left(\beta^{-}\right)^{\mathrm{g}}$ \\
\hline${ }^{82} \mathrm{Zn}$ & 0.075 & $0.228 \mathrm{~s}\left(\beta^{-}\right)^{\mathrm{i}}$ & $0.216 \mathrm{~s}\left(\beta^{-}\right)^{\mathrm{g}}$ \\
\hline${ }^{83} \mathrm{Zn}$ & 0.095 & $0.117 \mathrm{~s}\left(\beta^{-}\right)^{\mathrm{i}}$ & $0.120 \mathrm{~s}\left(\beta^{-}\right)^{\mathrm{g}}$ \\
\hline${ }^{84} \mathrm{Zn}$ & 0.095 & $>633 \mathrm{~ns}\left(\beta^{-}\right)^{\mathrm{i}}$ & $0.103 \mathrm{~s}\left(\beta^{-}\right)^{\mathrm{g}}$ \\
\hline${ }^{85} \mathrm{Zn}$ & 0.095 & $>637 \mathrm{~ns}\left(\beta^{-}\right)^{\mathrm{i}}$ & $90.2 \mathrm{~ms}\left(\beta^{-}\right)^{\mathrm{g}}$ \\
\hline
\end{tabular}

\section{Table I (Continued)}

Calculated Single-Particle and Experimental Decay Properties of Zinc Systems with $54 \leq \mathrm{A} \leq \mathbf{8 8}$

\begin{tabular}{|c|c|c|c|}
\hline \multirow{2}{*}{ Nuclide } & \multirow{2}{*}{$a(A)$} & \multicolumn{2}{|c|}{ Half-Life (Decay Mode) } \\
\hline & & Experiment & This Work \\
\hline${ }^{86} \mathrm{Zn}$ & 0.095 & j & $79.4 \mathrm{~ms}\left(\beta^{-}\right)^{\mathrm{g}}$ \\
\hline${ }^{87} \mathrm{Zn}$ & 0.095 & j & $69.8 \mathrm{~ms}\left(\beta^{-}\right)^{\mathrm{g}}$ \\
\hline${ }^{88} \mathrm{Zn}$ & 0.095 & $\mathrm{j}$ & $61.9 \mathrm{~ms}\left(\beta^{-}\right)^{\mathrm{g}}$ \\
\hline
\end{tabular}

a The methodology of Ref. 22 is used to calculate the ${ }^{54} \mathrm{Zn}$ half-life. See Section 5.0.

${ }^{\mathrm{b}}$ Ref. 24.

${ }^{c}$ Allowed $1 f_{7 / 2}(p)$ to $1 f_{7 / 2}(n)$ positron decay transition.

${ }^{d}$ Allowed $2 p_{3 / 2}(p)$ to $2 p_{3 / 2}(n)$ positron decay transition.

${ }^{\text {e}}$ Allowed $2 p_{3 / 2}(p)$ to $2 p_{1 / 2}(n)$ positron decay transition.

${ }^{f}$ In view of the rapid variation of the half-life with $\mathrm{a}(\mathrm{A}),{ }^{65} \mathrm{Zn}$ and ${ }^{72} \mathrm{Zn}$ used an a(A) increment of 0.001 . Their half-life values are atypical of the trend in zinc isotopes in their vicinity.

g Allowed $2 p_{1 / 2}(n)$ to $2 p_{3 / 2}(p)$ beta decay transition.

${ }^{\mathrm{h}}$ First Forbidden $1 \mathrm{~g}_{9 / 2}(\mathrm{n})$ to $1 \mathrm{f}_{5 / 2}(\mathrm{p})$ beta decay transition.

${ }^{\mathrm{i}}$ Ref. 25

${ }^{\mathrm{j}}$ No data is provided in Ref. 24 or 25. 
The beta decay half-lives are determined following the log ft methodology of Wong ${ }^{26}$. Allowed (first forbidden) transition half-lives were derived using the values of $\log \mathrm{ft}=5$ (8). Given the uncertainties in the calculated level energies, second and higher forbidden transitions were not determined. Positron and electron capture half-lives were determined following the approach of Ref. 12.

The single-particle model is used to calculate the alpha, beta, positron, and electron capture decay half-lives. The $2 p$ decay mode is evaluated using the methodology of Ref. 27 . Since the $2 p$ decay mode involves two protons, it is not easily evaluated using a single-particle model. The methodology of Ref. 27 , as applied to the ${ }^{54} \mathrm{Zn}$ nucleus, is addressed in more detail in subsequent discussion.

\subsection{Selection of Experimental Half-Lives}

The half-life values and decay modes summarized in Ref. 24 were used as the basis for the experimental values utilized in this paper. Ref. 24 provides a consistent set of evaluated experimental data for the set of zinc isotopes noted in Table I. If Ref. 24 does not provide a value, the values of the data compilation of Ref. 25 are utilized in the Table I summary.

The reader should note that there are uncertainties in the experimental half-life values particularly for the lightest and heaviest zinc systems. For example, Ref. 24 provides a half-life of $3 \mathrm{~ms}$ for ${ }^{54} \mathrm{Zn}$. Other work ${ }^{27}$ calculates a half-life value of $3.03 \mathrm{~ms}$ for the ${ }^{54} \mathrm{Zn}$. Ref. 27 does not provides an estimates of an average ${ }^{54} \mathrm{Zn}$ half-life, but notes three experimental values: $3.7^{+2}-1,1.98^{+0.73}, 1.98^{+0.73}-0.41$, and $1.73^{+0.71}-0.47 \mathrm{~ms}$. Given the range of values that can be encountered for the lightest and heaviest $\mathrm{Zn}$ systems, the experimental half-life values of Ref. 24 are used in this paper to provide a consistent set of evaluated data for the zinc nuclei considered in this paper.

\subsection{Results and Discussion}

Using Eq. 2, the a(A) value was varied in increments of 0.005 to assess the applicability of the proposed model to predict the decay properties of $A \geq 54$ zinc isotopes. In view of uncertainties in the model and associated interaction, a smaller increment was not deemed to be justified unless noted in subsequent discussion. The issues associated with fitting all nuclei in this mass region with a single potential ${ }^{15-18}$ were noted previously.

Within the single particle model, ${ }^{54} \mathrm{Zn}-{ }^{58} \mathrm{Zn}$ nuclei fill the $1 \mathrm{f}_{7 / 2}$ neutron shell. ${ }^{54} \mathrm{Zn}$ is a $2 \mathrm{p}$ emitter and was evaluated using the methodology of Ref. $27 .{ }^{55} \mathrm{Zn}-{ }^{58} \mathrm{Zn}$ are positron emitters and were best fit a(A) values of 0.01 to 0.085 with an average value of 0.048 .

${ }^{59} \mathrm{Zn}$ to ${ }^{62} \mathrm{Zn}$ systems are positron emitters and best fit with $\mathrm{a}(\mathrm{A})$ values between -0.015 and 0.11 with an average value of about 0.066 . The ${ }^{59} \mathrm{Zn}$ to ${ }^{62} \mathrm{Zn}$ nuclei fill the $2 \mathrm{p}_{3 / 2}$ neutron shell.

${ }^{63} \mathrm{Zn}$ to ${ }^{68} \mathrm{Zn}$ systems fill the $1 \mathrm{f}_{5 / 2}$ neutron shell. ${ }^{63} \mathrm{Zn}$ is a positron emitter, ${ }^{64} \mathrm{Zn}$ and ${ }^{66} \mathrm{Zn}-{ }^{68} \mathrm{Zn}$ are stable nuclei, and ${ }^{65} \mathrm{Zn}$ decays by electron capture. These systems are all best fit using $\mathrm{a}(\mathrm{A})$ values between 0.04 and 0.075 with an average value of about 0.055 .

${ }^{69} \mathrm{Zn}$ to ${ }^{70} \mathrm{Zn}$ nuclei fill the $2 p_{1 / 2}$ neutron shell, and were best fit with a(A) values of 0.0 and $0.03 .{ }^{69} \mathrm{Zn}$ is a beta emitter and ${ }^{70} \mathrm{Zn}$ is a stable nucleus. The average $\mathrm{a}(\mathrm{A})$ value for the ${ }^{69} \mathrm{Zn}$ and ${ }^{70} \mathrm{Zn}$ systems is 0.015 .

The ${ }^{59} \mathrm{Zn}$ to ${ }^{70} \mathrm{Zn}$ results are consistent in the sense that the average $\mathrm{a}(\mathrm{A})$ values tend to decrease as the neutron 
shells fill. This trend holds for the $2 p_{3 / 2}, 1 f_{5 / 2}$, and $2 p_{1 / 2}$ neutron shells. However, as the neutron number increases to fill the $1 g_{9 / 2}, 2 d_{5 / 2}$, and $3 s_{1 / 2}$ shells, single-particle model effects are supplemented by other contributions. This is characterized by an increasing a $(A)$ value, which represents a greater contribution from other degrees of freedom including collective effects. A similar phenomenon was noted in Ref. 19 in the vicinity of ${ }^{70} \mathrm{Fe}$. Collective and other degrees of freedom effects, represented by an increasing a $(A)$ value, are noted in subsequent discussion.

${ }^{71} \mathrm{Zn}-{ }^{80} \mathrm{Zn}$ nuclei fill the $1 \mathrm{~g}_{9 / 2}$ neutron shell, and were best fit with $\mathrm{a}(\mathrm{A})$ values between -0.008 and 0.055 . The average $a(A)$ value was about 0.029 . This $a(A)$ value reverses the decreasing trend noted previously and is consistent with the transition from single-particle to other effects (e.g., collective and other degrees of freedom) noted in Ref. 19.

${ }^{81} \mathrm{Zn}$ to ${ }^{86} \mathrm{Zn}$ nuclei fill the $2 \mathrm{~d}_{5 / 2}$ neutron shell, and were best fit with $\mathrm{a}(\mathrm{A})$ values between 0.065 and 0.095 . The average $a(A)$ value for nuclei filling the $2 d_{5 / 2}$ neutron shell is about 0.087 that is consistent with the transition from singleparticle to collective and other effects ${ }^{10}$. Of these $2 d_{5 / 2}$ systems, only ${ }^{81} \mathrm{Zn}$ to ${ }^{83} \mathrm{Zn}$ have well-defined half-lives ${ }^{24}$ and ${ }^{84} \mathrm{Zn}$ and ${ }^{85} \mathrm{Zn}$ have measured half-life bounding values ${ }^{25}$. The ${ }^{84} \mathrm{Zn}$ and ${ }^{85} \mathrm{Zn}$ systems were best fit with an a(A) value 0.095 . Although, there is no decay data for the ${ }^{86} \mathrm{Zn}$ nucleus, it was also modeled using an a(A) value of 0.095 .

The heaviest zinc neutron excess systems (i.e., ${ }^{87} \mathrm{Zn}$ and ${ }^{88} \mathrm{Zn}$ ) fill the $3 \mathrm{~s}_{1 / 2}$ neutron shell. There is no decay data for the ${ }^{87} \mathrm{Zn}$ and ${ }^{88} \mathrm{Zn}$ nuclei ${ }^{24,25}$. Following our previous discussion, an a(A) value based on the heaviest zinc isotopes, with measured half-lives, is used to determine the half-lives of the ${ }^{87} \mathrm{Zn}$ and ${ }^{88} \mathrm{Zn}$ systems.

Spherical single-particle energy calculations produce reasonable results for the observed beta, positron, and electron capture decay modes. Using the methodology of Ref. 27 , a credible result is obtained for the ${ }^{54} \mathrm{Zn} 2 \mathrm{p}$ decay mode. No alpha decay transitions were predicted by the model calculations for the nuclei summarized in Table I.

Table I lists the half-life of the limiting decay transition (i.e., the transition that has the shortest decay half-life). For example, ${ }^{60} \mathrm{Zn}$ has two positron decay transitions that are possible within the scope of the aforementioned single-particle model (i.e., allowed $2 p_{3 / 2}(p)$ to $2 p_{3 / 2}(n)[2.42 \mathrm{~min}]$ and allowed $2 p_{3 / 2}(p)$ to $\left.2 p_{1 / 2}(n)[17.4 h]\right)$. For ${ }^{60} Z n$, the limiting positron decay mode is the allowed $2 p_{3 / 2}(p)$ to $2 p_{3 / 2}(n)[2.42 \mathrm{~min}]$ transition.

The model generally predicts the proper decay mode for $54 \leq \mathrm{A} \leq 88$ zinc nuclei ${ }^{24,25}$. The results for known zinc systems summarized in Table I suggest that the model predictions of the neutron excess zinc systems tend to improve as the number of neutrons increases.

The ${ }^{54} \mathrm{Zn}-{ }^{58} \mathrm{Zn}$ systems are the least massive zinc isotopes and fill the $1 \mathrm{f}_{7 / 2}$ neutron shell. ${ }^{54} \mathrm{Zn}$ is a $2 \mathrm{p}$ emitter and its decay half-life was evaluated following the effective liquid drop model (ELDM) approach of Gonçalves et al. ${ }^{27}$. The ELDM model was utilized for ${ }^{54} \mathrm{Zn}$ because a single- particle model is not directly applicable to a $2 p$ decay process. Using the ELDM approach ${ }^{27}$, the ${ }^{54} \mathrm{Zn} 2 \mathrm{p}$ decay mode half-life is calculated to be $4.35 \mathrm{~ms}$, which is in reasonable agreement with the experimental value of $3 \mathrm{~ms}^{24}$.

The single-particle model predicts a positron decay half-life of $1370 \mathrm{~ms}$ for ${ }^{54} \mathrm{Zn}$ using an a(A) value of 0.115 . However, this is not the limiting decay mode since the positron decay half-life is over 450 times larger than the $2 p$ decay half-life. The single-particle model correctly predicts the ${ }^{55} \mathrm{Zn},{ }^{56} \mathrm{Zn},{ }^{57} \mathrm{Zn}$, and ${ }^{58} \mathrm{Zn} \beta^{+}$decay modes, but overestimated theses half-lives by a factor of $48,25,14$, and 9 , respectively.

For nuclei filling the $2 p_{3 / 2}$ neutron shell, the model correctly predicts a $\beta^{+}$decay mode for ${ }^{59} \mathrm{Zn}-{ }^{62} \mathrm{Zn}$. Model results 
for ${ }^{59} \mathrm{Zn}$ and ${ }^{60} \mathrm{Zn}$ overestimate the $\beta^{+}$half-life by a factor of 3 and about $1 \%$, respectively. The ${ }^{61} \mathrm{Zn}$ and ${ }^{62} \mathrm{Zn} \beta^{+}$half-lives are underestimated by 10 and $62 \%$, respectively. Compared to the $1 f_{7 / 2}$ neutron shell, the results tend to improve as the $2 p_{3 / 2}$ neutron shell fills.

The $1 f_{5 / 2}$ neutron shell begins to fill in the ${ }^{63} \mathrm{Zn}$ system. The model predicts the correct $\beta^{+}$decay mode, but underestimates the measured ${ }^{63} \mathrm{Zn}$ half-life by $15 \% .{ }^{65} \mathrm{Zn}$ is correctly predicted by the model to decay by electron capture $(\mathrm{EC})$, but the associated half-life is overestimated by about $6 \% .{ }^{64} \mathrm{Zn}$, and ${ }^{66} \mathrm{Zn}-{ }^{68} \mathrm{Zn}$ complete filling the $1 \mathrm{f}_{5 / 2}$ neutron shell and are correctly predicted to be stable by the single-particle model.

${ }^{69} \mathrm{Zn}$ and ${ }^{70} \mathrm{Zn}$ fill the $2 \mathrm{p}_{1 / 2}$ neutron shell. The ${ }^{69} \mathrm{Zn} \beta$ - decay mode is correctly predicted by the model, and its halflive is overestimated by $18 \% .{ }^{70} \mathrm{Zn}$ is correctly predicted to be a stable nuclear system by the single-particle model.

The $1 \mathrm{~g}_{9 / 2}$ neutron shell is filled with $\mathrm{A}=71-80$ zinc systems. The ${ }^{71} \mathrm{Zn}-{ }^{80} \mathrm{Zn}$ systems are within $8 \%$ of experiment with an average underestimate of about $1.5 \%$. The model predicts the correct $\beta^{-}$decay mode for all the $1 \mathrm{~g}_{9 / 2}$ neutron shell zinc systems.

${ }^{81} \mathrm{Zn}-{ }^{86} \mathrm{Zn}$ fill the $2 d_{5 / 2}$ neutron shell. The ${ }^{81} \mathrm{Zn}-{ }^{83} \mathrm{Zn}$ are correctly predicted to decay by the $\beta$ - decay mode and are within about $5 \%$ of the experimental half-life values. The average error for these systems is about $0.4 \%$. The ${ }^{84} \mathrm{Zn}$ and ${ }^{85} \mathrm{Zn}$ systems are consistent with the experimental lower bounds ${ }^{25}$ and $\beta^{-}$decay mode, and have calculated half-lives of 103 and $90.2 \mathrm{~ms}$, respectively. ${ }^{86} \mathrm{Zn}$ is also predicted to decay by $\beta^{-}$emission with a half-life of $79.4 \mathrm{~ms}$. There is no experimental decay or half-life data for the ${ }^{86} \mathrm{Zn}$ system ${ }^{24,25}$.

The ${ }^{87} \mathrm{Zn}$ and ${ }^{88} \mathrm{Zn}$ systems fill the $3 \mathrm{~s}_{1 / 2}$ neutron shell. There is no experimental decay or half-life data for the these systems ${ }^{24,25}$. The single-particle model predicts both ${ }^{87} \mathrm{Zn}$ and ${ }^{88} \mathrm{Zn}$ systems decay by a $\beta^{-}$decay mode, and have calculated half-lives of 69.8 and $61.9 \mathrm{~ms}$, respectively.

No zinc isotopes with $A>88$ were predicted by the model used in this paper. The predicted $A=84-88$ systems have decreasing half-lives that are in the $60-100 \mathrm{~ms}$ range. Based on the ${ }^{83} \mathrm{Zn}$ results and comparisons to neutron excess $\mathrm{Z}=$ 20 and 26 systems ${ }^{9,10}$, the ${ }^{84} \mathrm{Zn}-{ }^{88} \mathrm{Zn}$ model predictions likely overestimate the beta-decay half-lives of these neutron excess nuclei. There are no half-life measurements for ${ }^{86} \mathrm{Zn}-{ }^{88} \mathrm{Zn}^{24,25}$. The calculated beta-decay half-life values for ${ }^{84} \mathrm{Zn}$ and ${ }^{85} \mathrm{Zn}$ are consistent with the initial experimental values of $>633 \mathrm{~ns}$ and $>637 \mathrm{~ns}$, respectively ${ }^{25}$. The $\mathrm{A}=84-88$ zinc nuclei are predicted to decay through an allowed $2 p_{1 / 2}(n)$ to $2 p_{3 / 2}(p)$ beta decay transition. This transition becomes the dominant decay pathway as the neutron shells fill in $A=69-88$ zinc nuclei.

The neutron (proton) single-particle energy levels for $A=83-88$ zinc nuclei are summarized in Tables II (III). These model results should facilitate comparison with other calculations including those from the shell model. The $A=83-88$ zinc nuclei results are important because they facilitate determination of the heaviest zinc nucleus. 
Table II

Neutron Single-Particle Binding Energies for ${ }^{83} \mathrm{Zn}-{ }^{88} \mathrm{Zn}$ Nuclei

Binding Energy (MeV)

Single-Particle Level

\begin{tabular}{|c|c|c|c|c|c|c|}
\hline & ${ }^{83} \mathrm{Zn}$ & ${ }^{84} \mathrm{Zn}$ & ${ }^{85} \mathrm{Zn}$ & ${ }^{86} \mathrm{Zn}$ & ${ }^{87} \mathrm{Zn}$ & ${ }^{88} \mathrm{Zn}^{\mathrm{a}}$ \\
\hline $1 s_{1 / 2}$ & 30.7 & 30.4 & 30.2 & 30.0 & 29.8 & 29.6 \\
\hline $1 p_{3 / 2}$ & 24.8 & 24.6 & 24.4 & 24.3 & 24.1 & 23.9 \\
\hline $1 p_{1 / 2}$ & 23.2 & 23.0 & 22.9 & 22.7 & 22.6 & 22.5 \\
\hline $1 d_{5 / 2}$ & 18.2 & 18.1 & 18.0 & 17.9 & 17.7 & 17.6 \\
\hline $1 d_{3 / 2}$ & 15.3 & 15.2 & 15.1 & 15.0 & 14.9 & 14.8 \\
\hline $2 s_{1 / 2}$ & 15.2 & 15.1 & 15.0 & 14.9 & 14.8 & 14.7 \\
\hline $1 f_{7 / 2}$ & 11.1 & 11.0 & 11.0 & 10.9 & 10.8 & 10.7 \\
\hline $2 p_{3 / 2}$ & 7.48 & 7.43 & 7.38 & 7.33 & 7.28 & 7.23 \\
\hline $1 f_{5 / 2}$ & 6.57 & 6.55 & 6.54 & 6.53 & 6.51 & 6.50 \\
\hline $2 p_{1 / 2}$ & 6.00 & 5.96 & 5.93 & 5.90 & 5.87 & 5.84 \\
\hline $1 g_{9 / 2}$ & 3.51 & 3.48 & 3.46 & 3.43 & 3.41 & 3.39 \\
\hline $2 d_{5 / 2}$ & 0.569 & 0.557 & 0.547 & 0.537 & 0.527 & 0.519 \\
\hline $3 s_{1 / 2}$ & 0.343 & 0.336 & 0.329 & 0.323 & 0.317 & 0.311 \\
\hline
\end{tabular}

a Since there are only 58 bound neutrons, ${ }^{88} \mathrm{Zn}$ is the last bound zinc system. 
Table III

Proton Single-Particle Binding Energies for ${ }^{83} \mathrm{Zn}-{ }^{88} \mathrm{Zn}$ Nuclei Binding Energy (MeV)

Single-Particle Level

\begin{tabular}{|c|c|c|c|c|c|c|}
\hline & ${ }^{83} \mathrm{Zn}$ & ${ }^{84} \mathrm{Zn}$ & ${ }^{85} \mathrm{Zn}$ & ${ }^{86} \mathrm{Zn}$ & ${ }^{87} \mathrm{Zn}$ & ${ }^{88} \mathrm{Zn}$ \\
\hline $1 s_{1 / 2}$ & 49.2 & 49.1 & 50.1 & 50.5 & 51.0 & 51.3 \\
\hline $1 p_{3 / 2}$ & 42.6 & 43.1 & 43.6 & 44.0 & 44.5 & 45.0 \\
\hline $1 p_{1 / 2}$ & 39.8 & 40.3 & 40.7 & 41.2 & 41.7 & 42.1 \\
\hline $1 d_{5 / 2}$ & 34.8 & 35.3 & 35.9 & 36.4 & 36.9 & 37. \\
\hline $2 s_{1 / 2}$ & 30.3 & 30.8 & 31.3 & 31.8 & 32.3 & 32.8 \\
\hline $1 d_{3 / 2}$ & 30.2 & 30.7 & 31.2 & 31.7 & 32.2 & 32.7 \\
\hline $1 f_{7 / 2}$ & 25.8 & 26.4 & 27.0 & 27.5 & 28.1 & 28.6 \\
\hline $2 p_{3 / 2}$ & 20.2 & 20.7 & 21.2 & 21.7 & 22.3 & 22.8 \\
\hline $1 f_{5 / 2}$ & 19.7 & 20.3 & 20.8 & 21.4 & 21.9 & 22.4 \\
\hline $2 p_{1 / 2}$ & 18.2 & 18.7 & 19.3 & 19.8 & 20.3 & 20.8 \\
\hline $1 g_{9 / 2}$ & 15.8 & 16.4 & 17.0 & 17.6 & 18.2 & 18.8 \\
\hline $2 d_{5 / 2}$ & 9.88 & 10.4 & 11.0 & 11.5 & 12.0 & 12 \\
\hline $1 g_{7 / 2}$ & 8.79 & 9.36 & 9.92 & 10.5 & 11.0 & 11 \\
\hline $3 s_{1 / 2}$ & 7.58 & 8.09 & 8.60 & 9.11 & 9.61 & \\
\hline
\end{tabular}

Table III (Continued)

Proton Single-Particle Binding Energies for ${ }^{83} \mathrm{Zn}-{ }^{88} \mathrm{Zn}$ Nuclei Binding Energy (MeV)

Single-Particle Level

\begin{tabular}{|l|l|l|l|l|l|l|}
\hline & ${ }^{83} \mathrm{Zn}$ & ${ }^{84} \mathrm{Zn}$ & ${ }^{85} \mathrm{Zn}$ & ${ }^{86} \mathrm{Zn}$ & ${ }^{87} \mathrm{Zn}$ & ${ }^{88} \mathrm{Zn}$ \\
\hline $2 \mathrm{~d}_{3 / 2}$ & 7.17 & 7.71 & 8.23 & 8.76 & 9.27 & 9.78 \\
\hline $1 \mathrm{~h}_{11 / 2}$ & 4.97 & 5.61 & 6.24 & 6.87 & 7.48 & 8.09 \\
\hline $2 \mathrm{f}_{7 / 2}$ & $\mathrm{a}$ & $\mathrm{a}$ & 0.924 & 1.43 & 1.93 & 2.43 \\
\hline
\end{tabular}

a Single-particle level is unbound.

The Table II results reemphasize the previous discussion that asserted ${ }^{88} \mathrm{Zn}$ was the heaviest bound zinc system. Table II notes that only 58 neutrons are bound by the model potential that terminates the bound zinc systems with mass 88 (30 protons and 58 neutrons). For A > 88 calculations only 58 bound neutrons occur. Within the proposed model, this precludes the existence of zinc nuclei heavier than mass 88. 


\subsection{Conclusions}

Single-particle level calculations suggest that neutron excess zinc isotopes terminate with ${ }^{88} \mathrm{Zn} . \mathrm{A}=84-88$ zinc isotopes have limited experimental half-life data, but the model predicts beta decay half-lives in the range of $60-100 \mathrm{~ms}$. Based on comparisons to lighter $Z=20$ and 26 excess neutron nuclei ${ }^{9,}{ }^{10}$, these results likely overestimate the experimental half-lives of these neutron excess zinc nuclei.

\section{References}

1. D. M. Siegel and B. D. Metzger, Phys. Rev. Lett. 119, 231102 (2017).

2) National Academy of Sciences Report No. 11796, Scientific Opportunities with a Rare-Isotope Facility in the United States, Washington DC: National Research Council (2007).

3) N. Fukuda, T. Kubo, D. Kameda, N. Inabe, H. Suzuki, Y. Shimizu, H. Takeda, K. Kusaka, Y. Yanagisawa, M. Ohtake, K. Tanaka, K. Yoshida, H. Sato, H. Baba, M. Kurokawa, T. Ohnishi, N. Iwasa, A. Chiba, T. Yamada, E. Ideguchi, S. Go, R. Yokoyama, T. Fujii, H. Nishibata, K. leki, D. Murai, S. Momota, D. Nishimura, Y. Sato, J. Hwang, S. Kim, O. B. Tarasov, D. J. Morrissey, and G. Simpson, J. Phys. Soc. Jpn. 87, 014202 (2018).

4) Y. Shimizu, T. Kubo, N. Fukuda, N. Inabe, D. Kameda, H. Sato, H. Suzuki, H. Takeda, K. Yoshida, G. Lorusso, H. Watanabe, G. S. Simpson, A. Jungclaus, H. Baba, F. Browne, P. Doornenbal, G. Gey, T. Isobe, Z. Li, S. Nishimura, P-A Söderström, T. Sumikama, J. Taprogge, Z. Vajta, J. Wu1, Z. Xu, A. Odahara, A. Yagi, H. Nishibata, R. Lozeva, C. Moon, and H-S Jung, J. Phys. Soc. Jpn. 87, 014203 (2018).

5) M. Bernas, C. Engelmann, P. Armbruster, S. Czajkowski, F. Ameil, C. Böcksteigel, Ph. Dessagne, C. Donzaud, H. Geissel, A. Heinz, Z. Janas, C. Kozhuharov, Ch. Miehe, G. Münzenberg, M. Pfützner, W. Schwab, C. Stéphan, K. Sümmerer, L. Tassan-Got, and B. Voss, Phys. Lett. B 415, 111 (1997).

6) J. Kurcewicz, F. Farinon, H. Geissel, S. Pietri, C. Nociforo, A. Prochazka, H. Weick, J. S. Winfield, A. Estradé, P. R. P. Allegro, A. Bail, G. Bélier, J. Benlliure, G. Benzoni, M. Bunce, M. Bowry, R. Caballero-Folch, I. Dillmann, A. Evdokimov, J. Gerl, A. Gottardo, E. Gregor, R. Janik, A. Kelić-Heil, R. Knöbel, T. Kubo, Y. A. Litvinov, E. Merchan, I. Mukha, F. Naqvi, M. Pfützner, M. Pomorski, Z. Podolyák, P. H. Regan, B. Riese, M. V. Ricciardi, C. Scheidenberger, B. Sitar, P. Spiller, J. Stadlmann, P. Strmen, B. Sun, I. Szarka, J. Taïeb, S. Terashima, J. J. Valiente-Dobón, M. Winkler, and P. Woods, Phys. Lett. B 717, 371 (2012).

7) T. Baumann, A. M. Amthor, D. Bazin, B. A. Brown, C. M. Folden, III, A. Gade, T. N. Ginter, M. Hausmann, M. Matoš, D. J. Morrissey, M. Portillo, A. Schiller, B. M. Sherrill, A. Stolz, O. B. Tarasov, and M. Thoennessen, Nature 449, 1022 (2007). 8) O. B. Tarasov, M. Portillo, D. J. Morrissey, A. M. Amthor, L. Bandura, T. Baumann, D. Bazin, J. S. Berryman, B. A. Brown, G. Chubarian, N. Fukuda, A. Gade, T. N. Ginter, M. Hausmann, N. Inabe, T. Kubo, J. Pereira, B. M. Sherrill, A. Stolz, C. Sumithrarachichi, M. Thoennessen, and D. Weisshaar, Phys. Rev. C 87, 054612 (2013).

9) J. J. Bevelacqua, Physics Essays 31, 462 (2018).

10) J. J. Bevelacqua, Physics Essays, 33, 175 (2020).

11) J. J. Bevelacqua, Decay Characteristics of Neutron Excess Fluorine Nuclei, QEIOS 
24XLL9, 1 (2020). https://doi.org/10.32388/24XLL9

12) A. Lukasiak and A. Sobiczewski, Acta Phys. Pol. B6, 147 (1975).

13) F. Petrovich, R. J. Philpott, D. Robson, J. J. Bevelacqua, M. Golin, and D. Stanley, Phys. Rev. Lett. 37, 558 (1976).

14) S. Hofmann and G. Münzenberg, Rev. Mod. Phys. 72, 733 (2000).

15) E. Rost, Phys. Lett. 26B, 184 (1968).

16) J. Blomqvist and S. Wahlborn, Ark. Fys. 16, 545 (1959).

17) L. Ray and P. E. Hodgson, Phys. Rev. C20, 2403 (1979).

18) N.Schwierz, I. Wiedenhöver, and A. Volya, arXiv:0709.3525v1 [nucl-th] 21 Sep 2007.

19) A. Gade, R. V. F. Janssens, J. A. Tostevin, D. Bazin, J. Belarge, P. C. Bender, S. Bottoni, M. P. Carpenter, B. Elman, S. J. Freeman, T. Lauritsen, S. M. Lenzi, B. Longfellow, E. Lunderberg, A. Poves, L. A. Riley, D. K. Sharp, D. Weisshaar, and S. Zhu, Phys. Rev. C99, $011301($ R) (2019)

20) C. Li, X. Xu, J. Li, G. Zhang, B. Li, C. A. T. Sokhna, Z. Ge, F. Zhang, P. Wen, F.-S. Zhang, Phys. Rev. C99, 024602 (2019).

21) O. V. Bespalova, I. N. Boboshin, V. V. Varlamov, T. A. Ermakova, B. S. Ishkhanov,

S. Yu. Komarov, E. A. Romanovskii, and T. I. Spasskaya, Bulletin of the Russian Academy of Sciences: Physics 74 (6), 850 (2010).

22) O. V. Bespalova, T. A. Ermakova, A. A. Klimochkina, E. A. Romanovskii, and T. I. Spasskaya, Bulletin of the Russian Academy of Sciences. Physics 76 (8), 843 (2012).

23) S. Bottoni, S. Zhu, R. V. F. Janssens, M. P.Carpenter, Y. Tsunoda, T. Otsuka, A. O. Macchiavelli, D. Cline, C. Y. Wu, A. D. Ayangeakaa, B. Bucher, M. Q. Buckner, C. M. Campbell, C. J. Chiara, H. L. Crawford, M. Cromaz, H. M. David, P. Fallon, A. Gade, J. P. Greene, J. Harker, A. B. Hayes, C. R. Hoffman, B. P. Kay, A. Korichi, T. Lauritsen, J. Sethi, D. Seweryniak, W. B. Walters, D. Weisshaar, and A. Wiens, Phys. Lett. B775, 271 (2017).

24) E. M. Baum, M. C. Ernesti, H. D. Knox, T. R. Miller, and A. M. Watson, Nuclides and Isotopes - Chart of the Nuclides, $17^{\text {th }}$ ed, Knolls Atomic Power Laboratory (2010).

25) National Nuclear Data Center, Brookhaven National Laboratory. NuDat (Nuclear Structure and Decay Data). http://www.nndc.bnl.gov/nudat2/ (accessed 26 January, 2020).

26) C. Y. Wong, Phys. Lett. 21, 688 (1966).

27) M.Gonçalves, N.Teruya, O.A.P.Tavares, and S.B.Duarte, Physics Letters B774, 14 (2017). 